\title{
Preclinical and clinical development of siRNA-based therapeutics
}

Gulnihal Ozcan ${ }^{1}$, Bulent Ozpolat ${ }^{1}$, Robert L. Coleman², Anil K. Sood ${ }^{2,3,4}$ and Gabriel LopezBerestein $^{1,4^{*}}$

Departments of ${ }^{1}$ Experimental Therapeutics, ${ }^{2}$ Gynecologic Oncology and Reproductive Medicine, and ${ }^{3}$ Cancer Biology and ${ }^{4}$ Center for RNA Interference and Non-Coding RNA, The University of Texas MD Anderson Cancer Center, Houston, TX, USA, 77030

The authors have no conflicts to report.

Keywords: siRNA, Gene silencing, Therapeutic use, Nanocarriers, Ovarian cancer, EphA2, Nanoliposomes 
*Correspondence to: Gabriel Lopez-Berestein, MD, Division of Cancer Medicine, Unit 1950,

P.O. Box 301429, Houston, Texas 77230,glopez@mdanderson.org 


\begin{abstract}
Discovery of RNA interference, first in plants and C. elegans and later in mammalian cells, led to the emergence of a transformative view in biomedical research. Knowledge of the multiple actions of non-coding RNAs has truly allowed viewing DNA, RNA and proteins in novel ways. Small interfering RNAs (siRNAs) can be used as tools to study single gene function both in vitro and in vivo and are an attractive new class of therapeutics, especially against undruggable targets for the treatment of cancer and other diseases. Despite the potential of siRNAs in cancer therapy, many challenges remain, including rapid degradation, poor cellular uptake and off-target effects. Rational design strategies, selection algorithms, chemical modifications and nanocarriers offer significant opportunities to overcome these challenges. Here, we review the development of siRNAs as therapeutic agents from early design to clinical trial, with special emphasis on the development of EphA2-targeting siRNAs for ovarian cancer treatment.
\end{abstract}




\section{Abbreviations}

2'-OMe: 2'-O-methyl, 2'-F: 2'-Fluoro, CH/TA: chitosan/thioaptamer, DOPC: 1,2-dioleoyl-snglycero-3-phosphatidylcholine, DOTAP: 1,2-dioleoyl-3-trimethylammonium-propane, DOTMA: $N$-[1-(2,3-dioleoyloxy)propyl]- $N, N, N$-trimethylammonium methyl sulfate, EA5: EphA2 agonistic antibody, EphA2: ephrin type-A receptor 2, GalNAc: $N$ acetylgalactosamine, IVT: intravitreal, LNAs: locked nucleic acids, MSV: multistage vector, OC: ovarian cancer, PEG: polyethylene glycol, PLA: polylactic acid, PLGA: poly(lactic-coglycolic) acid, PS: phosphorothioate, SLN: solid-lipid nanoparticles, SNALPs: stable nucleic acid-lipid particles, TTR: transthyretin. 


\section{Contents}

1. Introduction

1.1. RNA interference

1.2. Gene silencing by micro-RNAs

1.3. Gene silencing by small interfering RNAs

1.4. Challenges with siRNA-based therapeutics

1.4.1. Off-target effects

1.4.2. Efficacy

1.4.3. Delivery

1.4.4. Immune response and toxicity

2. Pre-clinical development of siRNA-based therapeutics

2.1. Rational design of siRNAs

2.2. In silico selection

2.3. Chemical modifications

2.4. Systemic delivery of siRNAs: nanocarriers

3. Clinical experience with siRNA-based therapeutics

3.1. Locally delivered siRNA-based therapeutics

3.2. Systemically delivered siRNA-based therapeutics

4. Targeting EphA2 with siRNA-based therapeutics

4.1. EphA2 as a target in cancer

4.2. Preclinical development of siRNA-EphA2-DOPC in ovarian cancer

4.3. Lessons learned

5. Conclusion and future perspectives 
Acknowledgements

References 


\section{Introduction}

\subsection{RNA interference}

RNA interference (RNAi) is an evolutionary conserved mechanism in which doublestranded RNA (dsRNA) molecules silence the post-transcriptional expression of homologous target genes. This phenomenon was first discovered in plants in the late 1980s [1] and then in C. elegans in 1998 by Fire et al. [2]. Demonstration of similar processes in mammalian cells in 2001 [3] led to the emergence of new tools to study gene function.

Small interfering RNA (siRNA) is a member of a family of non-coding RNAs (ncRNAs) that effect and regulate gene, RNA and protein function. ncRNAs can be classified into infrastructural ncRNAs that involve ribosomal, transfer, small nuclear and small nucleolar RNAs with well-known functions and regulatory ncRNAs that can be further classified into long ncRNAs (lncRNAs) and small ncRNAs based on transcript size. IncRNAs are transcripts ranging in length from 200 nucleotides (nt) to approximately 100 kilobases and are mostly involved in trafficking of protein complexes, genes and chromosomes to appropriate locations. They have been proposed to mediate epigenetic changes in a cell type-specific manner, by recruiting chromatin-remodeling complexes to specific genomic loci. Many different classes of small ncRNAs have been defined with distinct functions. Piwiinteracting RNAs (piRNAs) are small ncRNAs (24-31 nt in size) that can form complexes with Piwi proteins of the Argonaute family and play a role in suppression of transposon activity during germline development. Recently, promoter-associated RNAs (PARs) and enhancer RNAs (eRNAs) have been described as novel classes functioning in 
transcriptional regulation $[4,5]$. In addition to these, pyknons, which are nonrandom patterns of repeated elements found more frequently in 3'UTR regions of genes, are being classified under small ncRNAs with their possible involvement in posttranscriptional silencing of genes, mainly related to cell communication, regulation of transcription, signaling and transport [6]. Most well-known classes of small ncRNAs, namely micro-RNAs (miRNAs) and siRNAs, are the major mediators of RNAi and will be discussed in detail in following sections.

\subsection{Gene silencing by micro-RNAs}

miRNAs are small non-coding dsRNAs transcribed by the genome. Initially they were found as complex stem-loop or short hairpin structures called pri-miRNAs (Fig. 1). pri-miRNAs are processed by Drosha into pre-miRNAs in the nucleus, followed by transport of premiRNAs to the cytoplasm via exportin-5. A cytoplasmic RNAse III enzyme called Dicer cleaves the pre-miRNAs into shorter double-stranded miRNAs with imperfect complementarity. These short fragments are recognized by Argonaute 2 (AGO2) and RNAinduced silencing complex (RISC), where one of the strands is degraded and the other strand guides the AGO2-RISC complex to bind and block translation of target mRNAs having partial complementary sites typically located in the 3'UTR $[7,8]$. 


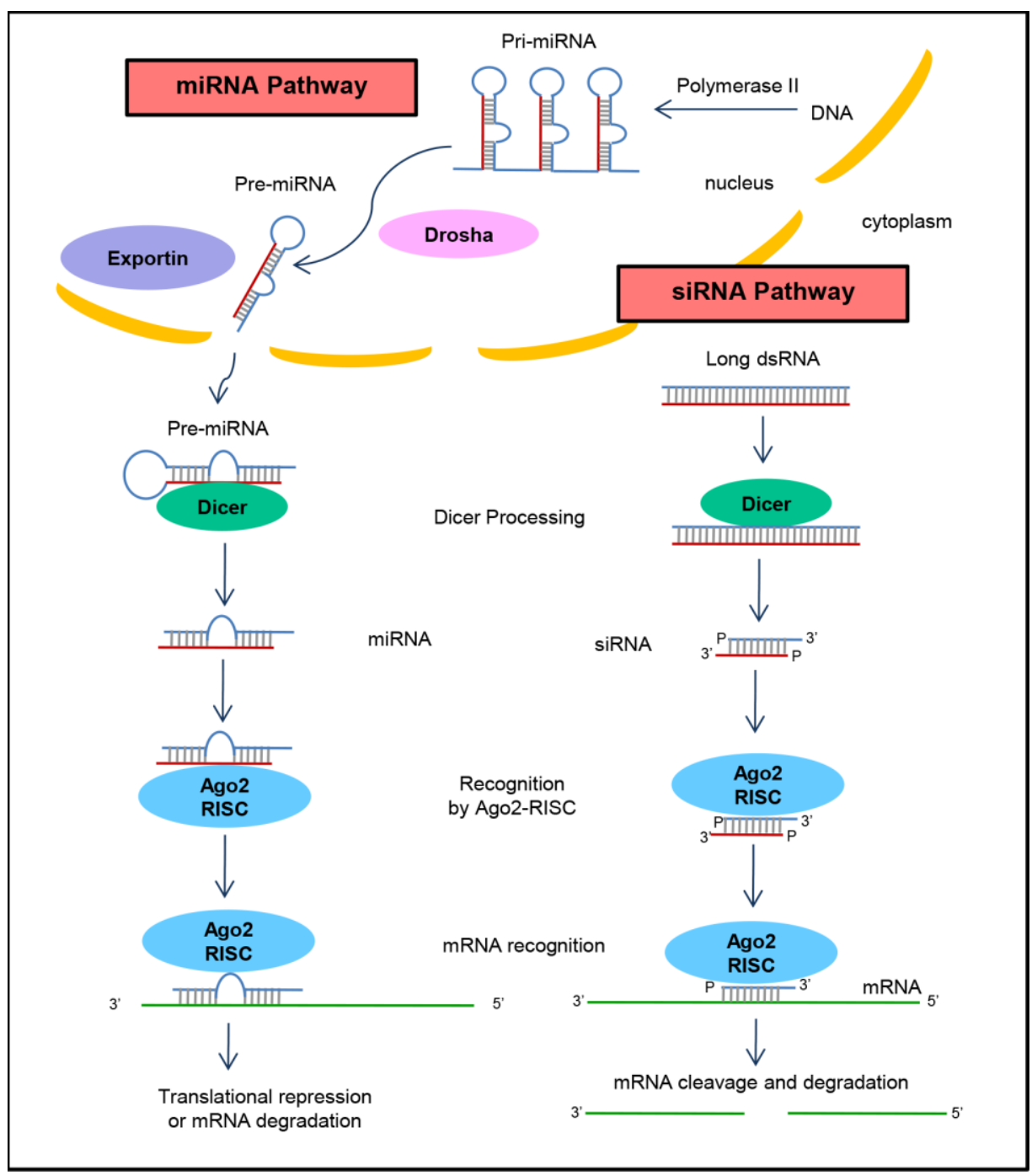

Fig. 1. The process of RNA interference in eukaryotic cells. Long precursor miRNA (called pri-miRNA) is processed by Drosha into pre-miRNAs in the nucleus. Following transportation to the cytoplasm via exportin-5, pre-miRNAs are further processed by an RNAse III enzyme called Dicer to produce shorter double-stranded miRNAs with imperfect complementarity. miRNAs are recognized by Argonaute 2 (AGO2) and RNA-induced silencing complex (RISC), where one of the strands is degraded and the other strand guides the AGO2-RISC complex to bind and block translation of target mRNAs having partial complementary sites. Cytoplasmic long double-stranded RNA (dsRNA) is cleaved by the 
cytosolic enzyme Dicer into small interfering RNAs (siRNAs). siRNAs are recognized by the AGO2-RISC enzyme complex. One of the strands is degraded and the other strand guides the complex to recognize mRNA sequences with perfect or nearly perfect complementarity, resulting in cleavage and degradation of target. 


\subsection{Gene silencing by small interfering RNAs}

siRNAs are synthetic mediators of RNAi that are dsRNA molecules of 21 to 23 base pairs (bp) in length designed specifically to silence expression of target genes. They can be introduced exogenously into the cell or organism in short (21-23 bp) form or in the form of long dsRNA molecules. These dsRNAs are processed by endogenous RNAi machinery after introduction into the cell (Fig. 1). First, the cytosolic enzyme Dicer cleaves long dsRNAs into shorter fragments (siRNAs), leaving two nucleotide (2-nt) 3' overhangs and 5' phosphate groups $[9,10]$. siRNAs are recognized by the AGO2-RISC enzyme complex, where one of the strands is degraded and the other (mostly antisense) strand is left as a guide to find target mRNA sequences. Unlike miRNAs, siRNAs bind sequences with perfect or nearly perfect complementarity and cause cleavage of targets instead of translational suppression $[11,12]$. Because they can efficiently silence target gene expression in a sequence-specific manner, siRNAs became indispensable tools to study the function of single genes $[11,13]$.

\subsection{Challenges with siRNA-based therapeutics}

\subsubsection{Off-target effects}

siRNAs are designed to knock down specific targets. However, recent studies have shown that they may also silence an unknown number of unintended genes. There are two mechanisms suggested to explain this off-target effect. First, siRNAs can tolerate several mismatches at the mRNA target and retain their ability to silence those targets with imperfect complementarity [14]. The second mechanism involves promiscuous entry of 
siRNAs into endogenous miRNA machinery [15]. miRNAs recognize targets with perfect complementarity to their 'seed regions' composed of nucleotides 2-8. Complementarity of remaining nucleotides has less importance for recognition. Because siRNAs are very nearly identical to the related class of miRNAs, they can recognize mRNAs with their seed region and lead to degradation of an unpredictable number of mRNAs [16].

\subsubsection{Efficacy}

During the past few years, a number of siRNAs and other ncRNAs, such as miRNAs, have been successfully used in experimental models. Data from preclinical models are now giving rise to translation of new siRNA (Table 1) and miRNA-based therapies into clinical trials. In the case of siRNAs, the target selection process is extensional, requiring a thorough mining of databases and pathways [17]. Different siRNAs targeting different parts of the same mRNA sequence have varying RNAi efficacies, and only a limited fraction of siRNAs has been shown to be functional in mammalian cells [18]. Among randomly selected siRNAs, 58-78\% were observed to induce silencing with greater than $50 \%$ efficiency and only $11-18 \%$ induced $90-95 \%$ silencing [19]. Some of the principles to design siRNAs are discussed in section 2.1.

\subsubsection{Delivery}

Delivery of siRNAs to target tissues is impeded by many barriers at different levels. siRNAs are easily filtered from the glomerulus and rapidly excreted from the kidney [20]. Together 
with rapid excretion kinetics, the susceptibility to degradation by nucleases is a major problem leading to short half-life (15 min to 1 hour) in plasma, potentially limiting the use of siRNAs [21,22]. However, some chemical modifications have been shown to protect siRNAs from nuclease degradation without interfering with siRNA silencing efficiency [23],

and some others, such as phosphorothioate (PS) modification or hydrophobic ligands (e.g., cholesterol), were shown to increase protein binding and extend serum lifetime $[24,26]$. Besides these, nanocarriers are important tools providing protection against both rapid renal excretion and nuclease cleavage during delivery of siRNAs to target tissues [26].

Unfavorable physicochemical properties such as negative charge, large molecule weight and size complicate passive diffusion of siRNAs through the cell membrane, which makes endocytosis the major way for internalization. This process adds new limitations at different stages of delivery to molecular targets, including endocytosis by tissue cells and release from endosomes into the cytoplasm [20,27].

\subsubsection{Immune response and toxicity}

RNAi is a mechanism involved in the innate immune response to protect cells from invasion by nucleic acids of pathogens such as viruses and bacteria. Several studies demonstrated that siRNAs itself can activate innate immunity by inducing interferon expression, even at low concentrations [28]. Protein kinase R (PKR) and toll-like receptor (TLR) 3 signaling pathways may be involved in sequence-independent immune activation by siRNAs. However, these mechanisms may play minor roles. Certain siRNAs stimulate 
production of proinflammatory cytokines via TLR 7 on dendritic cells and TLR 8 on monocytes in a sequence-dependent manner. These two pathways are being discussed as major mechanisms of immune activation by siRNAs. Some sequence motifs such as 5'UGUGU-3' [29] or 5'-GUCCUUCAA-3' [30], some secondary structures and uridine content of the sequence were identified as important for immune activation by these pathways. Chemical modifications such as 2'-O-methylation were shown to prevent immune activation by siRNAs. However, the exact rules of sequence-dependent immune activation are not known yet; hence potential therapeutic siRNAs must be tested for immunostimulatory effects prior to clinical applications [31].

Some cases in which immune response is not the underlying mechanism of toxicity have also been identified. Fedorov et al. observed sequence-dependent but target-independent toxic effects and reported a good correlation between toxicity and the presence of a 4-basepair motif (UGGC) or -AU- rich pentamers in siRNA sequences [32].

\section{Pre-clinical development of siRNA-based therapeutics}

\subsection{Rational design of siRNAs}

siRNA backbone selection is performed by the selection of potentially active, nontoxic and selective target inhibitors. This entails chemical synthesis of many distinct 21-mer siRNAs with 2-nt 3' overhangs. Alternative molecules-including blunt 19-mers, blunt 25-mers, blunt 27-mers and asymmetric 25/27-mers or 27/29-mers-that enter the RNAi 
machinery at different levels must also be considered [23]. Each of these siRNA sequences designed for the same target may display distinct efficacy, specificity and off-target profiles even without a guarantee of gene silencing [33]. Secondary structures and the nucleotide sequences of siRNAs have effects on efficacy, specificity and off-target profiles. On the basis of informational analysis of sequences with known efficacy and specificity, several rules have been formulated for rational design of siRNAs [33-35].

First of all, 2-nt overhangs at each 3'-end (typically UU or TT) are important for recognition of siRNAs by RNAi machinery [36]. Together with 2-nt overhangs, GC content of the sequence determines thermodynamic stability of siRNAs and should ideally be between 30 to $70 \%$ [37]. To avoid nucleotide sequences occupied by regulatory or translational proteins and exon-exon junctions, the target sequences are generally chosen 75-100 bases downstream of the start codon $[38,39]$. Inclusion or exclusion of specific nucleotides at particular positions (e.g., A/U at positions 10 and 19, a G/C at position 1) is also considered important for the specificity and efficacy of designed siRNAs [34]. Design rules in addition to those mentioned above have been reviewed elsewhere [33, 35], and several web-based tools are now available for the design of effective and target-specific siRNAs [38, 39].

\subsection{In silico selection}

Despite ongoing efforts to define precise rules for rational design, siRNAs designed by current algorithms are still prone to induce off-target effects. Therefore design procedures are usually followed by a BLAST (basic local alignment search tool) search for cross- 
reactive 21-bp siRNA sequences to ensure siRNA target specificity. In a study by Snøve et al., however, $75 \%$ of 359 published siRNA sequences were found to have a risk of inducing off-target effects despite being subjected to a BLAST search before use [14]. These data indicated that BLAST may miss short alignments such as complementary seed regions involved in the aforementioned mechanisms for off-target effects $[14,31]$. The Smith and Waterman algorithm for local sequence analysis is more sensitive for detection of short alignments [14]. Naito et al. have developed an algorithm that selects siRNAs with lower seed-target duplex stability, since they observed high correlation between seed-dependent off-target effect and the thermodynamic stability of the duplex between the seed region of the siRNA guide strand and its target mRNA [18]. Some others focus on selection of hyperfunctional siRNAs that work effectively even at low concentrations and thus induce fewer off-target effects [40]. Regardless of which algorithm is used to select effective and specific siRNAs, global gene expression analysis is an inevitable step, especially for siRNAs that will be carried into clinics $[31,41,42]$.

\subsection{Chemical modifications}

siRNAs are produced mostly by chemical synthesis of single-stranded oligonucleotides that are annealed into a double-stranded form. This unmodified form is the major effector molecule of RNAi. However, chemical modifications at the sequence or structural level can help alleviate major obstacles for therapeutic use of siRNAs [23, 38]. 
A variety of chemical modifications may improve nuclease stability of siRNAs. While making these modifications, some rules should be considered such as preserving a free hydroxyl or phosphate group at the 5' end of the sense strand to retain siRNA cleavage activity [31]. Direct modification of internucleotide phosphate linkage is the simplest approach used to achieve nuclease resistance. Modification of the 2'-position of the ribose can decrease susceptibility of internucleotide phosphate linkage to nuclease cleavage and increase stability of the duplex. However, heavy 2'-O-methyl (2'-OMe) modification can significantly reduce silencing efficiency of siRNAs [43,44]. 2'-Fluoro (2'-F) modifications are known to increase nuclease resistance without causing a significant compromise in efficiency. However, there are some questionable findings about the safety and effectiveness of such modifications in nuclease resistance $[45,46]$. Combinations of ribose modifications with phosphate backbone modifications offer further improvement in serum stability and efficacy. We achieved enhanced stability and an increase (up to six-fold) in silencing efficacy of ephrin type-A receptor 2 (EphA2) siRNA by combining 2'-OMe with PS modification [47]. Modification with locked nucleic acids (LNAs) is another strategy to increase stability and nuclease resistance; however, it carries a risk of hepatotoxicity $[48,49]$. An inverted-dT base or other non-nucleotide groups placed at the 3 ' overhang was shown to protect against nuclease cleavage [50]. Another alternative strategy to increase stability while retaining potency is the substitution of DNA bases into siRNAs [51,52].

Several chemical modifications were shown to be effective in reducing off-target effects. Replacement of the guide strand seed region by deoxynucleotides [53], placing a single 2'OMe residue at position +2 of the guide strand [54] and selective placement of LNA 
residues [55] are some examples of these modifications. Off-target effects can also be reduced by limiting incorporation of the sense strand into the RISC complex. Modification of the 5' phosphate group [56] and use of small internally segmented siRNAs where the sense-strand is cleaved and annealed as two short segments to an intact anti-sense strand [57] are other strategies serving this purpose.

siRNA-induced immune activation can be limited by replacement of uridines with their 2'F, 2'-deoxy or 2'-OMe modified counterparts. These modifications have been shown to abrogate immune recognition of siRNAs by TLRs [31]. In particular, 2'-OMe-modified siRNAs inhibited production of TNF-alpha induced by their unmodified immunostimulatory counterparts even at very low concentrations [58].

The choice of modification pattern depends on specific siRNA sequence, route of delivery and aim of the application. It should be kept in mind that all these modifications can decrease the potency of siRNAs to varying degrees. The situation is even more complex with longer siRNAs. Because there are no precise rules to predict the effect of a modification, empirical testing is needed to ensure that the resulting molecule is still effective and retains the desired properties [23].

\subsection{Systemic delivery of siRNAs: nanocarriers}

Rational design strategies and chemical modifications have substantially improved some of the problems involved with siRNA-based therapeutics. However, poor cellular uptake 
remains an important issue that requires the use of carriers to facilitate siRNA uptake into the cells. Nanocarriers not only have great potential to improve cellular uptake but also promise reduction in siRNA-related toxicities, prevention of off-target effects and improvement in pharmacokinetic profiles of siRNA-based therapeutics [59].

Nanocarriers are small size particles (ranging from 1 to $300 \mathrm{~nm}$ ) that can carry and deliver drugs, oligonucleotides, peptides or desired cargos to target tissues. Various nanocarriers have been used for siRNA delivery in biomedical applications. Based on surface charge, size and hydrophobicity they have unique tissue biodistribution, toxicity and tumor cell uptake profiles. The nanomaterials used in the fabrication process-such as natural or synthetic lipids (e.g., liposomes, micelles), polymers (e.g., chitosan, polylactic-co-glycolic acid , polylactic acid, polyethilenimine), carbon nanotubes, quantum dots, magnetic nanoparticles and others [60-65]-determine the attributes of the resulting carrier.

Liposomes are composed of a phospholipid bilayer that forms upon the exposure of a dried lipid film to water. Liposomes have potential benefits for the delivery of siRNAs and have been widely used in diverse formulations for this purpose [60]. Liposomes based on cationic lipids, such as DOTAP (1,2-dioleoyl-3-trimethylammonium-propane) and DOTMA ( $N$-[1-(2,3-dioleoyloxy)propyl]- $N, N, N$-trimethylammonium methyl sulfate), can efficiently take up and condense siRNA and easily interact with negatively charged cell surfaces, facilitating delivery into cells. However, high intracellular stability and low release of siRNA contents have limited effect on gene downregulation $[66,67]$. Challenges observed in mouse models, such as dose-dependent hepatotoxicity, pulmonary inflammation and 
immune response, should be addressed before their translation into clinical trials $[66,68]$.

We have used neutral 1,2-dioleoyl-sn-glycero-3-phosphatidylcholine (DOPC)-based nanoliposomes [69]. DOPC-nanoliposomes incorporating siRNAs against EphA2, FAK, neuropilin-2, TMRRS/ERG, IL-8, EF2K or Bcl-2 were shown to be active in orthotopic and subcutaneous xenograft models of various tumors [69-74]. They were found to be safe after single and repeated intravenous (i.v.) administration of liposomes for 4 weeks without any detectable distress, toxicity or immune response [69-71,73]. Additionally, delivery of siRNAs in vivo into tumor cells was 10 -fold and 30 -fold more effective than it was with cationic liposomes (DOTAP) and naked siRNAs, respectively $[69,70]$.

Solid lipid-based technologies utilizing positively charged carriers including stable nucleic acid-lipid particles (SNALPs) and solid-lipid nanoparticles (SLN) $[75,76]$ have been developed for systemic delivery of siRNAs. Altough they have high serum stability and high efficiency in gene silencing, toxicity induced by other cationic lipid-based carriers may pose a challenge [76].

Lipidoid particles that utilize cholesterol and polyethylene glycol (PEG)-coated lipids for delivery of specific siRNAs were shown to provide gene silencing at lower doses of siRNA than those required by the original SNALP formulation, resulting in reduced toxicity [76]. In addition to these, lipophilic siRNA conjugates such as cholesterol conjugates have been designed for siRNA delivery but require significant improvement in efficacy and safety profiles $[77,78]$. 
Polymeric nanocarriers are useful tools for in vivo applications because of their safety. Nanoparticles made of natural polymers such as chitosan and atelocollagen have been shown to be highly effective for in vivo delivery of siRNAs $[61,62,72,79]$. Synthetic polyethilenimine-based nanocarriers offer several advantages including high transfection efficiency and endosomal escape. However, their use is limited by their cytotoxic effects [77,78]. Furthermore, poly(lactic-co-glycolic) acid (PLGA) or polylactic acid (PLA)-based nanoparticles [26], quantum dots [80,81] and magnetic iron oxide particles [64] have been studied for siRNA delivery with promising results.

Targeted delivery (active delivery) of therapeutics into tumor cells and/or tumor vasculature is another advance offered by use of nanocarriers. In general, high-affinity ligands such as functional peptides, lipophilic molecules, PEG and aptamers are attached to the exterior surface of nanoparticles to increase the delivery of therapeutics into the tumor tissue. Functionalizing of the surface of nanoparticles with proteins such as folate receptor alpha, transferin receptor, alphaVbeta3/5 integrin receptors and prostate specific membrane antigen (PSMA) holds great promise for enhanced tumor delivery of siRNAs [60].

\section{Clinical experience with siRNA-based therapeutics}

After validation in in vivo models, siRNA-based therapies were introduced into clinical trials. Since the discovery of RNAi, there have been more than 50 clinical trials involving 26 
different siRNAs (Table 1). Initial studies were conducted in diseases requiring localized delivery. Later, with the improvements in nanocarrier technology, systemically delivered siRNA-based therapeutics outnumbered the ones locally delivered $[82,83]$. An overview of clinical trials using siRNA-based therapeutics delivered by different methods is provided here.

\subsection{Locally delivered siRNA-based therapeutics}

Local delivery of siRNAs offer advantages for diseases involving tissues externally accessible or locally restricted. To date, locally delivered siRNAs have been used in clinical trials for diseases mostly involving the eye, such as age-related macular degeneration (AMD), diabetic macular edema (DME) and glaucoma and a small number of other diseases involving respiratory syncytial virus (RSV) infections, pachyonychia congenita and pancreatic ductal adenocarcinoma.

The first siRNA clinical trial in the field was initiated by Opko Health Inc. in 2004, utilizing bevasiranib, a siRNA targeting vascular endothelial growth factor (VEGF) to inhibit retinal neovascularization in patients with AMD and diabetic macular edema. Safety and efficacy of a single intravitreal (IVT) injection of bevasiranib was tested first in AMD patients, followed by a trial in DME patients. Biological activity was observed in phase I and II clinical trials. However, phase III trial was terminated early due to poor efficacy in reducing vision loss, which was the primary endpoint of the trial. Another phase III trial was designed to test safety and effectiveness of three doses of IVT bevasiranib as maintenance 
therapy for AMD following initiation of anti-VEGF therapy with three doses of ranibizumab (Lucentis). However, the trial was withdrawn prior to enrollment. Later, two different siRNAs, AGN211745 (Allergan) and PF-04523655 (Quark Pharmaceuticals), which target vascular endothelial growth factor receptor-1 (VEGFR1) [84] and proangiogenic protein RTP801 [85], respectively, were tested for the same indications. In phase I, the drugs were found be safe and well-tolerated. However, trials for both of these two molecules were terminated at phase II, due to inability to achieve primary objectives as in the case for bevasiranib.

In 2007, Alnylam Pharmaceuticals started to test the safety, tolerability and efficacy of intranasal ALN-RSV01, a siRNA targeting nucleocapsid protein of RSV. Phase II trials found ALN-RSV01 nasal spray and nebulizer to be safe and well tolerated in RSV-infected lung transplant patients [86]. It was also claimed that it may have beneficial effects on long-term allograft function in lung transplant patients infected with RSV. However, no phase III trial has been announced yet.

The first mutation-specific siRNA, TD101, was designed against keratin 6A N171K mutant in the rare skin disorder pachyonychia congenita. Intralesional injection of TD101 was found to be safe and effective. However, patients experienced intense pain during injection; therefore less painful delivery formulations such as ointment with lipid-based carriers and dissolvable microneedle arrays are being developed [87]. 
SYL040012 (bamosiran, by Sylentis, S.A.), targeting $\beta 2$-adrenergic receptor, was shown to decrease intraocular pressure in normotensive and hypertensive animal models [88]. In a phase I trial initiated in 2009, SYL040012 eye drops was reported to be safe and welltolerated. Two different phase II trials investigated tolerability and efficacy in subjects with ocular hypertension or open angle glaucoma. A double-masked, randomized, controlled study is being conducted to assess the safety and ocular efficacy of four different doses of SYL040012 compared with timolol maleate in patients with elevated intraocular pressure. The second siRNA drug from Sylentis, SYL1001, which targets transient receptor potential cation channel subfamily V member 1 (TRPV1), was tested for ocular pain associated with dry eye syndrome. Phase I study was completed, and participants are currently being recruited for phase II.

In 2010, QPI-1007 was designed by Quark Pharmaceuticals to target caspase-2, an enzyme involved in apoptosis. IVT injection of QPI-1007 was found safe in optic atrophy and nonarteritic anterior ischemic optic neuropathy patients in phase I. A phase II trial is now recruiting patients to test safety and efficacy in acute primary angle-closure glaucoma.

The siRNA siG12D, which targets mutant KRAS (KRASG12D), was designed by Silenseed Ltd. for pancreatic ductal adenocarcinoma. siG12D was encapsulated in a biodegradable polymer Local Drug EluteR (LODER) for controlled and prolonged delivery [89]. To assess efficacy and local distribution after injection by an endoscopic ultrasound (EUS) needle, a phase I trial was conducted in patients with locally advanced adenocarcinoma of the pancreas. A phase II study to assess efficacy of siG12D LODER in combination with 
gemcitabine or folfirinox chemotherapy was announced in patients with unresectable locally advanced pancreatic cancer.

\subsection{Systemically delivered siRNA-based therapeutics}

To date, 12 clinically tested siRNA-based therapeutics have been administered by the i.v. route. All but one of these siRNAs are carried by synthetic carriers, mostly SNALP.

The first clinical trial utilizing a systemically delivered siRNA was initiated in August 2007 by Quark Pharmaceuticals. QPI-1002 (I5NP), targeting proapoptotic protein p53, was tested for prevention of delayed graft function in patients undergoing kidney transplantation from deceased donors. Because uncoated siRNAs tend to accumulate in the kidneys, carrier was not used to deliver the siRNA to target tissue. Safety data in phase I was favorable and temporary suppression of p53 was achieved. Hence clinical development of QPI-1002 preceded by phase II trials, with results not currently published.

An siRNA-mediated effect by systemic delivery was first demonstrated in a clinical trial for human solid tumor (melanoma) started in 2008 by Calando Pharmaceuticals. In that study, CALAA-01, an siRNA targeting ribonuclease reductase (RRM2), was delivered using a cyclodextrin-based polymer coated with human transferrin for selective uptake by transferrin receptor highly expressed in tumor cells [90]. This was the first siRNA trial utilizing a nanocarrier. However, dose-limiting toxicity was observed in several patients [91], and the trial was terminated. 
With improvements in nanocarrier technology, the number of clinical trials utilizing systemically delivered siRNAs has increased at a growing pace. In 2009, three new systemically delivered siRNA-nanocarrier formulations were entered into clinical trials.

Tekmira Pharmaceuticals developed SNALP formulation for delivery of siRNAs by i.v. injection. Anti-ApoB siRNA encapsulated with SNALP, PRO-040201 (TKM-ApoB), was tested in hypercholesterolemia. Although the drug was well tolerated in phase I with efficacy in lowering LDL cholesterol, the trial was terminated due to the potential for immune stimulation and transient reductions in cholesterol levels [83]. However, development processes are continuing with improved nanoparticle carriers. Alnylam Pharmaceuticals developed ALN-VSP02, with two distinct siRNAs targeting kinesin spindle protein (KSP) and VEGF, in a partnership with Tekmira for the use of SNALP as carrier. In phase I, ALN-VSP02 was well tolerated and an anti-VEGF effect was observed in patients with advanced solid tumors with liver involvement. An extension study was then initiated in patients who responded to therapy in phase I, to collect long term safety data. Silence Therapeutics designed AtuPLEX, which is a cationic lipoplex with negatively charged nucleic acids. Atu027, a siRNA targeting protein kinase N3 (PKN3) carried in AtuPLEX, was shown to cause stabilization or regression of disease with no dose-dependent toxicities in patients with advanced solid tumors [92]. A phase Ib/IIa trial is currently being conducted to evaluate the safety and activity of Atu027 in combination with standard gemcitabine treatment in patients with advanced or metastatic pancreatic adenocarcinoma. 
Alnylam Pharmaceuticals conducted two sequential phase I trials in 2010 and 2012 with two different LNP formulations of a transthyretin (TTR) targeting siRNA: ALN-TTR01 and ALN-TTR02 (patisiran) for TTR-mediated amyloidosis. In both trials rapid, dose-dependent and sustained lowering of TTR levels was achieved. In one patient, protein knockdown of $81 \%$ was even observed, $50 \%$ of which was sustained for 28 days. Patisiran was shown to be superior to ALN-TTR01 in terms of potency and lower incidence of infusion-related reactions, which were the only noticeable adverse reactions in the trials [93]. On the basis of these promising results for the treatment of patients with transthyretin amyloidosis, phase II and III trials are now being conducted to investigate safety, tolerability and efficacy of patisiran. Later, Alnylam designed subcutaneous formulation revusiran (ALNTTRSC) by conjugating siRNA to $N$-acetylgalactosamine (GalNAc). In phase I, dosedependent knockdown of serum TTR was achieved in healthy volunteers. A phase II extension study is now being conducted to evaluate long-term safety in TTR-cardiac amyloidosis. Also, a phase III multicenter study of revusiran was started in December 2014 to evaluate safety and efficacy of revusiran in patients with TTR-mediated familial amyloidotic cardiomyopathy.

In 2011, Tekmira Pharmaceuticals started clinical trial with its second SNALP-carried siRNA-based therapeutic. TKM-PLK1, targeting polo kinase-1, was tested in solid tumors with liver involvement. The drug was well tolerated in phase I trial. Currently two distinct phase II trials are recruiting participants to determine safety and efficacy in hepatocellular carcinoma or neuroendocrine tumors and adrenocortical carcinoma. The same year, Alnylam initiated a phase I clinical trial with ALN-PCS02, targeting proprotein convertase 
subtilisin/kexin type 9 (PCSK9) in subjects with elevated LDL cholesterol. With i.v. injection of ALN-PCS02, a 70\% reduction in circulating PCSK9 plasma protein and a 40\% reduction in LDL cholesterol from baseline were achieved relative to placebo in healthy volunteers [94]. In a second phase I trial, a subcutaneous formulation of the drug, ALNPCSSC, is being tested for the same indication.

Investigational product TKM-100201, targeting various Ebola virus components, was designed by Tekmira. However, phase I trial initiated in 2012 was terminated by corporate decision to reformulate the product. Phase I trial for TKM-100802, the second siRNA-based therapeutic of Tekmira targeting Ebola virus, has been suspended following a clinical hold placed on the drug.

Nitto Denko Corporation tested safety and tolerability of ND-L02-s0201 injection, a vitamin A-coupled lipid nanoparticle containing siRNA against heat shock protein 47 (HSP47), in healthy normal subjects. After completion of phase I, safety and efficacy of ND-L02-s0201 injection are being tested in subjects with moderate to extensive fibrosis (METAVIR F3-4).

Alnylam Pharmaceuticals' other GalNAc-conjugated siRNA formulation, ALN-AT3SC, which targets antithrombin, began testing in phase I in 2014 for further evaluation in hemophilia A and B. Dicerna Pharmaceuticals announced two distinct trials in 2014 for DCR-MYC, an LNP carrying siRNA against MYC for hepatocellular carcinoma and solid tumors, multiple myeloma, or non-Hodgkin lymphoma. Comprehensive Cancer Center of Wake Forest University in collaboration with NCI also announced a phase I trial in 2014. Intravenous 
injection of peripheral blood mononuclear cells transfected with siRNA against E3 ubiquitin ligase Cbl-b will be tested in patients with melanoma, kidney cancer, pancreatic cancer or other solid tumors that are metastatic or cannot be removed by surgery. Lastly, a phase I clinical trial is on the way with siRNA-EphA2-DOPC in patients with ovarian cancer (OC) at the MD Anderson Cancer Center. In the next section, we will discuss findings and our experience in development of siRNA-EphA2-DOPC as a siRNA-based therapeutic for OC. 


\section{Table 1}

\section{siRNA-based therapeutics in clinical trials}

\begin{tabular}{|c|c|c|c|c|c|c|c|c|c|}
\hline $\begin{array}{l}\text { Start } \\
\text { date- } \\
\text { End date }\end{array}$ & Drug & Target & Vehicle & Route & Condition & Phase & Status & $\begin{array}{l}\text { Clinical Trial } \\
\text { ID }\end{array}$ & Sponsors \\
\hline 2004-2007 & $\begin{array}{l}\text { Bevasiranib } \\
\text { (Cand5) }\end{array}$ & VEGF & NC & IVT & Macular degeneration & 1 & Compl & NCT00722384 & $\begin{array}{l}\text { OPKO } \\
\text { Health, Inc. }\end{array}$ \\
\hline 2005-2007 & & & & & Diabetic macular edema & II & Compl & NCT00259753 & \\
\hline 2006-2007 & & & & & Macular degeneration & ॥ & Compl & NCT00306904 & \\
\hline 2007-2009 & & & & & $\begin{array}{l}\text { Age-related macular } \\
\text { degeneration }\end{array}$ & III & Term & NCT00499590 & \\
\hline Nov 2009- & & & & & & III & Wd & NCT00557791 & \\
\hline $\begin{array}{l}2004-2007 \\
2007-2009\end{array}$ & $\begin{array}{l}\text { AGN211745 } \\
\text { (siRNA-027) }\end{array}$ & VEGFR1 & NC & IVT & $\begin{array}{l}\text { Age-related macular } \\
\text { degeneration, } \\
\text { Choroidal } \\
\text { neovascularization }\end{array}$ & $\begin{array}{l}1 / 11 \\
I 1\end{array}$ & $\begin{array}{l}\text { Compl } \\
\text { Term }\end{array}$ & $\begin{array}{l}\text { NCT00363714 } \\
\text { NCT00395057 }\end{array}$ & $\begin{array}{l}\text { Allergan siRNA } \\
\text { Therap. Inc. }\end{array}$ \\
\hline 2008-2010 & & & & & $\begin{array}{l}\text { Diabetic retinopathy } \\
\text { Diabetes complications }\end{array}$ & II & Term & NCT00701181 & \\
\hline 2009-2011 & & & & & $\begin{array}{l}\text { Choroidal neovasc. } \\
\text { Diabetic retinopathy }\end{array}$ & ॥ & Compl & NCT00713518 & \\
\hline 2012-2013 & & & & & Diabetic macular edema & II & Compl & NCT01445899 & \\
\hline $\begin{array}{l}2007 \text { Jul- } \\
\text { Nov }\end{array}$ & ALN-RSV01 & $\begin{array}{l}\text { RSV-N } \\
\text { gene }\end{array}$ & & Nasal & $\begin{array}{l}\text { Respiratory syncytial virus } \\
\text { Infections }\end{array}$ & II & Compl & NCT00496821 & $\begin{array}{l}\text { Alnylam } \\
\text { Pharma }\end{array}$ \\
\hline $\begin{array}{l}2008-2009 \\
2010-2012\end{array}$ & & & & Nebul. & & II & $\begin{array}{l}\text { Compl } \\
\text { Compl }\end{array}$ & $\begin{array}{l}\text { NCT00658086 } \\
\text { NCT01065935 }\end{array}$ & \\
\hline 2007-2010 & $\begin{array}{l}\text { I5NP } \\
\text { (QPI-1002) }\end{array}$ & P53 & NC & IV & $\begin{array}{l}\text { Injury of kidney } \\
\text { Acute renal failure }\end{array}$ & 1 & Compl & NCT00802347 & Quark Pharma \\
\hline 2008- & & & & & & 1 & Term & NCT00683553 & \\
\hline $\begin{array}{l}2008 \text { Jan- } \\
\text { Aug }\end{array}$ & TD101 & $\begin{array}{l}\text { K6A } \\
\text { N171K }\end{array}$ & NC & $\begin{array}{l}\text { Int.les. } \\
\text { inj. }\end{array}$ & Pachyonychia congenita & 1 & Compl & NCT00716014 & $\begin{array}{l}\text { Pachyonychia } \\
\text { Congenita } \\
\text { Project }\end{array}$ \\
\hline 2008-2012 & CALAA-01 & RRM2 & $\begin{array}{l}\text { CyD NP, } \\
\text { transferri } \\
n, \text { PEG }\end{array}$ & IV & Solid tumors & 1 & Term & NCT00689065 & $\begin{array}{l}\text { Calando } \\
\text { Pharma }\end{array}$ \\
\hline 2009-2011 & ALN-VSP02 & $\begin{array}{l}\mathrm{KSP} \text { and } \\
\text { VEGF }\end{array}$ & SNALP & IV & $\begin{array}{l}\text { Advanced solid tumors } \\
\text { with liver involvement }\end{array}$ & 1 & Compl & NCT00882180 & $\begin{array}{l}\text { Alnylam } \\
\text { Pharma }\end{array}$ \\
\hline 2010-2012 & & & & & & 1 & Compl & NCT01158079 & \\
\hline 2009-2010 & $\begin{array}{l}\text { PRO-040201 } \\
\text { (TKM-ApoB) }\end{array}$ & Apo B & SNALP & IV & Hypercholesterolemia & 1 & Term & NCT00927459 & $\begin{array}{l}\text { Tekmira } \\
\text { Pharma }\end{array}$ \\
\hline 2009-2012 & Atu027 & PKN3 & $\begin{array}{l}\text { Cationic } \\
\text { lipoplex }\end{array}$ & IV & Advanced solid tumors & 1 & Compl & NCT00938574 & $\begin{array}{l}\text { Silence } \\
\text { Therapeutics }\end{array}$ \\
\hline 2013-2015 & & & & & $\begin{array}{l}\text { Pancreatic ductal } \\
\text { carcinoma }\end{array}$ & $\mathrm{lb} / \mathrm{lla}$ & Active & NCT01808638 & $\mathrm{GmbH}$ \\
\hline
\end{tabular}




\begin{tabular}{|c|c|c|c|c|c|c|c|c|c|}
\hline 2009-2010 & $\begin{array}{l}\text { SYL040012 } \\
\text { (Bamosiran) }\end{array}$ & $\beta 2-A R$ & NC & Ophth. & $\begin{array}{l}\text { Ocular hypertension } \\
\text { Open angle glaucoma }\end{array}$ & 1 & Compl & NCT00990743 & Sylentis, S.A. \\
\hline 2010-2012 & & & & & & $1 / I 1$ & Compl & NCT01227291 & \\
\hline 2012-2013 & & & & & & ॥ & Compl & NCT01739244 & \\
\hline 2014-2015 & & & & & & II & Recrt. & NCT02250612 & \\
\hline 2010-2013 & QPI-1007 & Caspase-2 & NC & IVT & $\begin{array}{l}\text { Optic atrophy } \\
\text { Non-arteritic anterior } \\
\text { Ischemic optic } \\
\text { neuropathy }\end{array}$ & 1 & Compl & NCT01064505 & Quark Pharma \\
\hline 2013-2015 & & & & & $\begin{array}{l}\text { Acute primary angle- } \\
\text { closure, glaucoma, }\end{array}$ & ॥ & Recrt. & NCT01965106 & \\
\hline 2010-2012 & ALN-TTR01 & TTR & LNP & IV & $\begin{array}{l}\text { TTR-mediated } \\
\text { amyloidosis }\end{array}$ & 1 & Compl & NCT01148953 & $\begin{array}{l}\text { Alnylam } \\
\text { Pharma }\end{array}$ \\
\hline 2012-2012 & $\begin{array}{l}\text { Patisiran } \\
\text { (ALN-TTR02) }\end{array}$ & & & & & 1 & Compl & NCT01559077 & \\
\hline 2012-2014 & & & & & & II & Compl & NCT01617967 & \\
\hline 2013-2017 & & & & & & II & Recrt. & NCT01961921 & \\
\hline 2013-2017 & & & & & & III & Recrt. & NCT01960348 & \\
\hline 2014-2014 & & & & & & 1 & Active & NCT02053454 & \\
\hline 2013-2015 & $\begin{array}{l}\text { Revusiran } \\
\text { (ALN-TTRSC) }\end{array}$ & & $\begin{array}{l}\text { SiRNA- } \\
\text { GalNAc }\end{array}$ & SC & TTR-cardiac amyloidosis & 1 & Recrt. & NCT01814839 & \\
\hline 2013-2015 & & & conjug. & & & II & Active & NCT01981837 & \\
\hline 2014-2017 & & & & & & II & Recrt. & NCT02292186 & \\
\hline 2011-2013 & SIG12D LODER & $\begin{array}{l}\text { KRAS } \\
\text { G12D }\end{array}$ & $\begin{array}{l}\text { LODER } \\
\text { Polymer }\end{array}$ & $\begin{array}{l}\text { EUS } \\
\text { biopsy }\end{array}$ & $\begin{array}{l}\text { Pancreatic ductal } \\
\text { adenocarcinoma }\end{array}$ & 1 & Compl & NCT01188785 & Silenseed Ltd \\
\hline 2015-2017 & & & & needle & & II & $\begin{array}{l}\text { Not } \\
\text { yet } \\
\text { recrt. }\end{array}$ & NCT01676259 & \\
\hline 2011-2012 & SYL1001 & TRPV1 & NC & Ophth. & $\begin{array}{l}\text { Ocular pain } \\
\text { Dry eye syndrome }\end{array}$ & 1 & Compl & NCT01438281 & Sylentis, S.A. \\
\hline 2012-2014 & & & & & & $1 / 11$ & Recrt. & NCT01776658 & \\
\hline 2011-2012 & $\begin{array}{l}\text { TKM-080301 } \\
\text { (TKM-PLK1) }\end{array}$ & $\begin{array}{l}\text { Polo- } \\
\text { Kinase-1 }\end{array}$ & SNALP & IV & $\begin{array}{l}\text { Solid tumors with liver } \\
\text { involvement }\end{array}$ & 1 & Compl & NCT01437007 & $\begin{array}{l}\text { National } \\
\text { Cancer Inst. }\end{array}$ \\
\hline 2010-2014 & & & & & $\begin{array}{l}\text { Neuroendocrine tumors } \\
\text { Adrenocortical carcinoma }\end{array}$ & $1 / 11$ & Recrt. & NCT01262235 & $\begin{array}{l}\text { Tekmira } \\
\text { Pharma }\end{array}$ \\
\hline 2014-2016 & & & & & Hepatocellular carcinoma & $1 / I 1$ & Recrt. & NCT02191878 & \\
\hline 2011-2012 & ALN-PCS02 & PCSK9 & SNALP & IV & $\begin{array}{l}\text { Elevated LDL-cholesterol } \\
\text { (LDL-C) }\end{array}$ & 1 & Compl & NCT01437059 & $\begin{array}{l}\text { Alnylam } \\
\text { Pharma }\end{array}$ \\
\hline 2014-2015 & ALN-PCSSC & & & SC & & 1 & Active & NCT02314442 & \\
\hline 2012 & $\begin{array}{l}\text { TKM-100201 } \\
\text { (TKM-Ebola) }\end{array}$ & $\begin{array}{l}\text { ZEBOV L } \\
\text { polym., } \\
\text { VP24, } \\
\text { VP35 }\end{array}$ & LNP & IV & Ebola virus infection & 1 & Term & NCT01518881 & $\begin{array}{l}\text { Tekmira } \\
\text { Pharma }\end{array}$ \\
\hline 2013-2014 & ND-L02-s0201 & HSP47 & LNP & IV & Healthy & 1 & Compl & NCT01858935 & $\begin{array}{l}\text { Nitto Denko } \\
\text { Corp. }\end{array}$ \\
\hline 2014-2016 & & & & & $\begin{array}{l}\text { Moderate to extensive } \\
\text { hepatic fibrosis }\end{array}$ & 1 & Recrt. & NCT02227459 & \\
\hline 2014 & TKM-100802 & & LNP & IV & Ebola virus infection & 1 & Susp & NCT02041715 & $\begin{array}{l}\text { Tekmira } \\
\text { Pharma }\end{array}$ \\
\hline 2014-2015 & ALN-AT3SC & AT & $\begin{array}{l}\text { siRNA- } \\
\text { GalNAc } \\
\text { conjug. }\end{array}$ & SC & $\begin{array}{l}\text { Hemophilia A } \\
\text { Hemophilia B }\end{array}$ & I & Recrt. & NCT02035605 & $\begin{array}{l}\text { Alnylam } \\
\text { Pharma }\end{array}$ \\
\hline
\end{tabular}




\begin{tabular}{|c|c|c|c|c|c|c|c|c|c|}
\hline 2014-2016 & APN401 & $\begin{array}{l}\text { E3 } \\
\text { Ubiquitin } \\
\text { ligase } \\
\text { Cbl-b }\end{array}$ & $\begin{array}{l}\text { Mononc. } \\
\text { cells }\end{array}$ & IV & $\begin{array}{l}\text { Melanoma } \\
\text { Pancreatic cancer } \\
\text { Renal cell cancer }\end{array}$ & 1 & $\begin{array}{l}\text { Not } \\
\text { yet } \\
\text { recrt. }\end{array}$ & NCT02166255 & $\begin{array}{l}\text { Wake Forest } \\
\text { Univ. }\end{array}$ \\
\hline 2014-2016 & DCR-MYC & MYC & LNP & IV & Hepatocellular carcinoma & $1 / I I$ & Recrt. & NCT02314052 & $\begin{array}{l}\text { Dicerna } \\
\text { Pharma }\end{array}$ \\
\hline 2014-2015 & & & & & $\begin{array}{l}\text { Solid tumors } \\
\text { Multiple myeloma } \\
\text { Non-Hodgkins lymphoma }\end{array}$ & 1 & Recrt. & NCT02110563 & \\
\hline 2015 & $\begin{array}{l}\text { siRNA-EphA2- } \\
\text { DOPC }\end{array}$ & EphA2 & $\begin{array}{c}\text { Neutral } \\
\text { liposome }\end{array}$ & IV & Advanced cancers & 1 & $\begin{array}{l}\text { Not } \\
\text { yet } \\
\text { recrt. }\end{array}$ & NCT01591356 & $\begin{array}{l}\text { MD Anderson } \\
\text { Cancer Center }\end{array}$ \\
\hline
\end{tabular}

AT: antithrombin, $\beta 2$-AR: $\beta 2$ adrenergic receptor, Comp.: completed, CyD: cyclodextrin, EUS: endoscopic ultrasound, Int. les. inj.: intralesional injection, IV: intravenous, IVT: intravitreal, K6A N171K: keratin 6A N171K mutant, KRASG12D: K-ras G12D mutant, KSP: kinesin spindle protein, LNP: lipid nanoparticle, LODER: Local drug eluter, RRM2: M2 subunit of ribonucleotide reductase, Mononc. Cells: mononuclear cells, NC: no carrier, Nebul.: nebulization, Ophth.: ophthalmic administration, PEG: polyethylene glycol, PCSK9: proprotein convertase subtilisin/kexin type 9, PKN3: protein kinase N3, Recrt.: recruiting, RSV N-gene: respiratory syncytial virus nucleocapsid gene, siRNA-GalNAc conjug.: siRNA conjugated to an $N$-acetylgalactosamine, SNALP: stable nucleic acid-lipid particles, Term.: terminated, TTR: transthyretin, VEGF: vascular endothelial growth factor, VEGFR1: vascular endothelial growth factor receptor 1, VP24: viral protein 24, VP35: viral protein 35, Wd.: withdrawn, ZEBOV L polym.: ZEBOV L polymerase. 


\section{Targeting EphA2 with siRNA-based therapeutics}

\subsection{EphA2 as a target in cancer}

EphA2 is a transmembrane protein from the ephrin family of receptor protein-tyrosine kinases. It is involved in neuronal development during embryogenesis $[95,96]$, and in adult humans it is primarily expressed by epithelial cells [97]. The role of EpHA2 in normal epithelia is not clearly understood, but it is thought to have a role in negative regulation of cell growth and migration. EphA2 is overexpressed in many human cancers, including melanoma, breast, prostate, esophageal and lung carcinomas [98-102]. High levels of EphA2 protein expression are associated with aggressive features in tumors and tumor models, showing tumorigenic and metastatic functions $[98,103]$.

OC is the fifth most-common cause of cancer in females and the leading cause of death from gynecological malignancies [104]. Most patients have high-grade disease with metastasis at the time of diagnosis due to vague clinical symptoms at early stages. The 5-year survival rate for patients with advanced disease is very low despite cytoreductive surgery and chemotherapy combination regimens $[105,106]$. Therefore there is an urgent need for new therapeutic strategies. Targeting EphA2 represents an attractive therapeutic strategy in OC for several reasons.

We observed that EphA2 was overexpressed in $76 \%$ of samples from 79 patients with epithelial OC. Furthermore EphA2 expression was not detectable in either the normal ovarian surface epithelium or in any observed epithelial inclusion cysts within the 
underlying stroma. In patients with OC, EphA2 overexpression was associated with highstage and high-grade disease [107]. High level of EphA2 protein expression is also significantly associated with a shorter patient survival, and EphA2 was shown to be an important prognostic marker for OC [108]. Consistent with these findings, laboratory models suggested active contribution of high EphA2 expression to aggressive cancer cell behavior [109]. Additionally, EphA2 overexpression in both the tumor and endothelial cells in clinical samples of $\mathrm{OC}$ is associated with increased markers of angiogenesis and invasion [110]. EphA2 signaling is particularly appealing because of the potential to target both tumor cells and the tumor-associated vasculature. Furthermore, low expression or absence of EphA2 in epithelial tissues including kidney, lung, colon and bladder [111] may be associated with low toxicity rates in therapeutic targeting of the molecule.

Carcinogenic properties of EphA2 were primarily observed in high levels of the unphosphorylated form. Therefore decreasing total EphA2 levels was thought to be a more effective strategy than blocking its activation. Various strategies such as antibody-mediated downregulation and siRNA-mediated gene silencing have been utilized to reduce EphA2 expression. We observed the efficacy and antivascular effects of EphA2 reduction with the agonistic antibody EA5 in OC. EA5 led to reduced EphA2 expression by inducing phosphorylation of the EphA2 receptor, followed by internalization and destruction. In combination with paclitaxel, EA5 substantially reduced tumor growth in an orthotopic OC model, including a paclitaxel-resistant model [112]. However, EA5-induced EphA2 phosphorylation is also known to activate other pathways, such as the mitogen-activated protein kinase pathway [113]. Because a siRNA-based strategy silences gene expression 
and prevents activation of receptor-induced pathways, we have focused on siRNA-based strategies and developed neutral DOPC liposomes carrying siRNAs directed against EphA2 (siRNA-EphA2-DOPC). Use of our newly developed EphA2 siRNA-carrying DOPC liposome in an orthotopic mouse model of OC resulted in decreased protein expression in the tumor and remarkably decreased tumor growth when combined with chemotherapy. With systemic administration of these liposomes, we have achieved prolonged and sustained target gene downregulation. Furthermore, we have demonstrated that EphA2-targeting siRNA in combination with paclitaxel significantly reduced tumor growth by $67 \%$ to $82 \%$ compared with nonspecific siRNA and paclitaxel [69]. In addition, our data support the hypothesis that neutral DOPC-nanoliposomes effectively deliver siRNA into tumor cells and can be combined with other conventional anti-cancer therapies, such as chemotherapy, to enhance the efficacy of conventional drugs.

In an attempt to achieve prolonged and sustained delivery of siRNA-EphA2-DOPC, we preferred the use of a multistage vector (MSV) delivery system. We loaded liposomal siRNAs into the 40- to $65-\mathrm{nm}$-size pores inside the $1.6-\mathrm{mm}$ hemispherical porous silicon particles. After i.v. administration, the silicon particles travel in circulation and settle at the tumor vasculature, where porous silicon degrades gradually and releases the liposomal siRNA. With this new delivery system, we have shown that knockdown of EphA2 expression lasted for as long as 3 weeks from a single administration, resulting in reduced tumor cell proliferation and tumor angiogenesis and eventually in reduced tumor growth. Our results also indicated that the MSV delivery system did not cause significant toxicity to major organs such as liver and kidney [114]. Furthermore, we have developed 
chitosan/thioaptamer ( $\mathrm{CH} / \mathrm{TA})$ nanoparticles that are capable of cell type-specific binding and delivery of siRNA into tumor-associated endothelial cells within the context of the Nanotechnology Platforms for Targeting Ovarian Cancer Vasculature project at MD Anderson. Intravenous administration of $\mathrm{CH} / \mathrm{TA}$ nanoparticles into mice with HeyA8 ovarian tumors resulted in successful binding of aptamer to endothelial cells as well as delivery of siRNA into tumors [115]. We have also shown that the administration of chitosan nanoparticles conjugated with cyclic Arg-Gly-Asp (RGD) led to increased tumor delivery and enhanced anti-tumor activity in OC models [116].

\subsection{Preclinical development of siRNA-EphA2-DOPC in ovarian cancer}

We have previously demonstrated that neutral nanoliposomes are effective carriers for nucleotides in diverse animal models [117-120]. A DOPC loaded with antisense oligonucleotides against Grb2 is currently in advanced phase I clinical trial in leukemia [121], and no safety issues have been observed in this trial so far. We selected a DOPCbased siRNA, siRNA-EphA2-DOPC, for use in OC and other orthotopic animal models [6973]. There was a clear anti-tumor effect of siRNA-EphA2-DOPC in the animal models tested. We started the preclinical development by establishing kinetics of EphA2 downregulation in vivo in OC. On the basis of these studies, we determined that siRNA-EphA2-DOPC could silence EphA2 in OC for up to 6 days. Therefore we selected twice-weekly i.v. administration in order to maintain continuous silencing of EphA2 in tumors (for details, see ref. 69). Once we had established the kinetics of inhibition and the single and multiple dose safety in a relevant mouse model, we proceeded to studies in non-human primates. 
The safety of siRNA-EphA2-DOPC was clearly demonstrated in these animals, with no hematologic effects or any organ toxicity following necropsy.

A phase I clinical trial of siRNA-EphA2-DOPC was recently authorized by the FDA [122]. All elements of manufacturing and quality controls were completed within the Investigational New Drug (IND) application.

\subsection{Lessons learned}

Obviously this process is not a rapid one. Early discussions with the FDA are encouraged, and any recommendation should be followed. The manufacturing of siRNA and DOPC and the formulation were all performed under good manufacturing practices (GMP) and the toxicology studies followed good laboratory practice (GLP). One factor to consider is the homology of the human target and the murine target. High homology is ideal; otherwise, safety studies should be conducted in at least two species. The process from target discovery to IND approval spanned a period of more than 10 years. The learning process of drug development with nucleotides is a work in progress, but with such progress we can move these promising technologies more expeditiously to clinical application.

\section{Conclusion and future perspectives}

siRNA-based therapeutics hold great potential for cancer therapy and treatment of other diseases. However, many challenges, including rapid degradation, poor cellular uptake and 
off-target effects, need to be addressed in order to carry these molecules into clinical trials. These new class of therapeutics holds great promise for the treatment of various cancers by targeting signaling pathways and oncogenes that promote cell proliferation, cell cycle progression, invasion/metastasis and resistance mechanisms in tumors. Improvements in rational design strategies, selection algorithms, chemical modifications and nanocarriers have the potential to make the translational process faster and more effective in the near future and to open the door to development of highly effective and safe therapeutics for clinical applications.

\section{Acknowledgements}

This study was supported by grants to G. Lopez-Berestein: NCI-U54CA096300, NCIP50PKCA093459, CA151668, CA180145, NCI-CA151668, NCI-UH2TR00943; and to A.K. Sood: Department of Defense grant W81XWH-09-1-0212; NIH grants U54CA143837, U54CA151668, RC2GM092599, and P50 CA083639; the CPRIT grant RP121071 from the State of Texas; the RGK Foundation; the Gilder Foundation; and the Ernest Cockrell Jr. Distinguished Endowed Chair. 


\section{References}

[1] R. Jorgensen, Altered gene expression in plants due to transinteractions between homologous genes, Trends. Biotechnol. 8(12) (1990) 340-344.

[2] A. Fire, S. Xu, M.K. Montgomery, S.A. Kostas, S.E. Driver, C.C. Mello, Potent and specific genetic interference by double-stranded RNA in Caenorhabditis elegans, Nature 391 (1998) 806-811.

[3] S.M. Elbashir, J. Harborth, W. Lendeckel, A. Yalcin, K. Weber, T. Tuschl, Duplexes of 21-nucleotide RNAs mediate RNA interference in cultured mammalian cells, Nature 24(411) (2001) 494-498.

[4] M.U. Kaikkonen, M.T. Lam, C.K. Glass, Non-coding RNAs as regulators of gene expression and epigenetics, Cardiovasc. Res. 90(3) (2011) 430-440.

[5] P.J. Batista, H.Y. Chang, Long noncoding RNAs: cellular address codes in development and disease, Cell 152(6) (2013) 1298-1307.

[6] J. Sana, P. Faltejskova, M. Svoboda, O. Slaby, Novel classes of non-coding RNAs and cancer, J Transl. Med. 10 (2012) 103. 
[7] S.M. Hammond, A.A. Caudy, G.J. Hannon, Post-transcriptional gene silencing by double-stranded RNA, Nat Rev Genet. 2 (2) (2001) 110-119.

[8] L. He, G.J. Hannon, MicroRNAs: small RNAs with a big role in gene regulation, Nat Rev Genet. 5 (7) (2004) 522-531.

[9] G. Meister, T. Tuschl, Mechanisms of gene silencing by double-stranded RNA, Nature 431 (2004) 343-349.

[10] H. Siomi, M.C. Siomi, On the road to reading the RNA-interference code, Nature 457 (2009) 396-404.

[11] A. de Fougerolles, H.P. Vornlocher, J. Maraganore, J. Lieberman, Interfering with disease: a progress report on siRNA-based therapeutics, Nat Rev Drug Discov. 6 (6) (2007) 443-453.

[12] D.H. Kim, J.J. Rossi, Strategies for silencing human disease using RNA interference, Nat Rev Genet. 8(3) (2007) 173-184.

[13] C.V. Pecot, G.A. Calin, R.L. Coleman, G. Lopez-Berestein, A.K. Sood, RNA interference in the clinic: challenges and future directions, Nat Rev Cancer. 11(1) (2011) 59-67. 
[14] O. Snøve Jr., T. Holen, Many commonly used siRNAs risk off-target activity, Biochem Biophys Res Commun. 319 (1) (2004) 256-263.

[15] J.G. Doench, C.P. Petersen, P.A. Sharp, siRNAs can function as miRNAs, Genes Dev. 17 (2003) 438-442.

[16] A.L. Jackson, J. Burchard, J. Schelter, B.N. Chau, M. Cleary, L. Lim, P.S. Linsley, Widespread siRNA "off-target" transcript silencing mediated by seed region sequence complementarity, RNA. 12 (7) (2006) 1179-1187.

[17] S.M. Yiu, P.W. Wong, T.W. Lam, Y.C. Mui, H.F. Kung, M. Lin, Y.T. Cheung, Filtering of ineffective siRNAs and improved siRNA design tool, Bioinformatics 21(2) (2005) 144-151.

[18] Y. Naito, K. Ui-Tei, Designing functional siRNA with reduced off-target effects, Methods Mol Biol. 942 (2013) 57-68.

[19] A.M. Chalk, C. Wahlestedt, E.L. Sonnhammer, Improved and automated prediction of effective siRNA, Biochem Biophys Res Commun. 319 (1) (2004) 264-274.

[20] R. Juliano, M.R. Alam, V. Dixit, H. Kang, Mechanisms and strategies for effective delivery of antisense and siRNA oligonucleotides, Nucleic Acids Res. 36 (12) (2008) 4158-4171. 
[21] D.W. Bartlett, M.E. Davis, Effect of siRNA nuclease stability on the in vitro and in vivo kinetics of siRNA-mediated gene silencing, Biotechnol Bioeng. 97 (4) (2007) 909921.

[22] A.A. Volkov, N.S. Kruglova, M.I. Meschaninova, A.G. Venyaminova, M.A. Zenkova, V.V. Vlassov, E.L. Chernolovskaya, Selective protection of nuclease-sensitive sites in siRNA prolongs silencing effect, Oligonucleotides, 19(2) (2009) 191-202.

[23] M.A. Behlke, Chemical modification of siRNAs for in vivo use, Oligonucleotides, 18 (4) (2008) 305-319.

[24] D.A. Braasch, Z. Paroo, A. Constantinescu, G. Ren, O.K. Oz, R.P. Mason, D.R. Corey, Biodistribution of phosphodiester and phosphorothioate siRNA, Bioorg. Med. Chem. Lett. 14 (2004) 1139-1143.

[25] J. Soutschek, A. Akinc, B. Bramlage, K. Charisse, R. Constien, M. Donoghue, S. Elbashir, A. Geick, P. Hadwiger, J. Harborth, M. John, V. Kesavan, G. Lavine, R.K. Pandey, T. Racie, K.G. Rajeev, I. Rohl, I. Toudjarska, G. Wang, S. Wuschko, D. Bumcrot, V. Koteliansky, S. Limmer, M. Manoharan, H.P. Vornlocher, Therapeutic silencing of an endogenous gene by systemic administration of modified siRNAs, Nature 432 (2004) 173-178. 
[26] B. Ozpolat, A.K. Sood, G. Lopez-Berestein, Nanomedicine based approaches for the delivery of siRNA in cancer, J. Intern. Med. 267 (1) (2010) 44-53.

[27] J. Wang, Z. Lu, M.G. Wientjes, J.L. Au, Delivery of siRNA therapeutics: barriers and carriers, AAPS J. 12(4) (2010) 492-503.

[28] M. Sioud, Deciphering the code of innate immunity recognition of siRNAs, Methods Mol Biol. 487 (2009) 41-59.

[29] A.D. Judge, V. Sood, J.R. Shaw, D. Fang, K. McClintock, I. MacLachlan, Sequencedependent stimulation of the mammalian innate immune response by synthetic siRNA, Nat Biotechnol. 23(4) (2005) 457-462.

[30] V. Hornung, M. Guenthner-Biller, C. Bourquin, A. Ablasser, M. Schlee, S. Uematsu, A. Noronha, M. Manoharan, S. Akira, A. de Fougerolles, S. Endres, G. Hartmann, Sequence-specific potent induction of IFN-alpha by short interfering RNA in plasmacytoid dendritic cells through TLR7, Nat Med. 11(3) (2005) 263-270.

[31] M. Sioud, Does the understanding of immune activation by RNA predict the design of safe siRNAs? Front Biosci. 13 (2008) 4379-4392. 
[32] Y. Fedorov, E.M. Anderson, A. Birmingham, A. Reynolds, J. Karpilow, K. Robinson, D. Leake, W.S. Marshall, A. Khvorova, Off-target effects by siRNA can induce toxic phenotype, RNA, 12(7) (2006) 1188-1196.

[33] M. Sioud, M. Leirdal, Potential design rules and enzymatic synthesis of siRNAs, Methods Mol Biol. 252 (2004) 457-469.

[34] B. Jagla, N. Aulner, P.D. Kelly, D. Song, A. Volchuk, A. Zatorski, D. Shum, T. Mayer, D.A. De Angelis, O. Ouerfelli, U. Rutishauser, J.E. Rothman, Sequence characteristics of functional siRNAs, RNA 11 (6) (2005) 864-872.

[35] S. Takasaki, Methods for selecting effective siRNA sequences by using statistical and clustering techniques, Methods Mol Biol. 487 (2009) 1-39.

[36] S.P. Walton, M. Wu, J.A. Gredell, C. Chan, Designing highly active siRNAs for therapeutic applications, FEBS J. 277 (23) (2010) 4806-4813.

[37] B. Yuan, R. Latek, M. Hossbach, T. Tuschl, F. Lewitter, siRNA Selection Server: an automated siRNA oligonucleotide prediction server, Nucleic Acids Res. 32 (2004) W130-134.

[38] P.B. Hajeri, S.K. Singh, siRNAs: their potential as therapeutic agents--Part I. Designing of siRNAs, Drug Discov Today (17-18) (2009) 851-858. 
[39] L.A. Dawson, B.A. Usmani, Design, manufacture, and assay of the efficacy of siRNAs for gene silencing, Methods Mol Biol. 439 (2008) 403-419.

[40] X. Wang, X. Wang, R.K. Varma, L. Beauchamp, S. Magdaleno, T.J. Sendera, Selection of hyperfunctional siRNAs with improved potency and specificity, Nucleic Acids Res. $37(22)(2009)$ e152.

[41] O. Snøve Jr., M. Nedland, S.H. Fjeldstad, H. Humberset, O.R. Birkeland, T. Grünfeld, P. Saetrom, Designing effective siRNAs with off-target control, Biochem Biophys Res Commun. 325(3) (2004) 769-773.

[42] M. Hannus, M. Beitzinger, J.C. Engelmann, M.T. Weickert, R. Spang, S. Hannus, G. Meister. siPools: highly complex but accurately defined siRNA pools eliminate offtarget effects, Nucleic Acids Res. 42(12) (2014) 8049-8061.

[43] F. Czauderna, M. Fechtner, S. Dames, H. Aygun, A. Klippel, G.J. Pronk, K. Giese, J. Kaufmann, Structural variations and stabilising modifications of synthetic siRNAs in mammalian cells, Nucleic Acids Res. 31 (2003) 2705-2716.

[44] S. Choung, Y.J. Kim, S. Kim, H.O. Park, Y.C. Choi, Chemical modification of siRNAs to improve serum stability without loss of effi cacy. Biochem. Biophys. Res. Commun. 342 (2006) 919-927. 
[45] F.C. Richardson, B.C. Tennant, D.J. Meyer, K.A. Richardson, P.C. Mann, G.R. Mcginty, J.L. Wolf, P.M. Zack, R.A. Bendele, An evaluation of the toxicities of 2'-fluorouridine and 2'-fl uorocytidine-HCl in F344 rats and woodchucks, Toxicol. Pathol. 27 (1999) 607-617.

[46] F.C. Richardson, C. Zhang, S.R. Lehrman, H. Koc, J.A. Swenberg, K.A. Richardson, R.A. Bendele, Quantification of 2'-fluoro-2'-deoxyuridine and 2'-fluoro-2'-deoxycytidine in DNA and RNA isolated from rats and woodchucks using LC/MS/MS, Chem. Res. Toxicol. 15 (2002) 922-926.

[47] S.Y. Wu, X. Yang, K.M. Gharpure, H. Hatakeyama, M. Egli, M.H. McGuire, A.S. Nagaraja, T.M. Miyake, R. Rupaimoole, C.V. Pecot, M. Taylor, S. Pradeep, M. Sierant, C. Rodriguez-Aguayo, H.J. Choi, R.A. Previs, G.N. Armaiz-Pena, L. Huang, C. Martinez, T. Hassell, C. Ivan, V. Sehgal, R. Singhania, H.D. Han, C. Su, J.H. Kim, H.J. Dalton, C. Kovvali, K. Keyomarsi, N.A. McMillan, W.W. Overwijk, J. Liu, J.S. Lee, K.A. Baggerly, G. Lopez-Berestein, P.T. Ram, B. Nawrot, A.K. Sood, 2'-OMe-phosphorodithioatemodified siRNAs show increased loading into the RISC complex and enhanced antitumour activity, Nat Commun. 5 (2014) 3459.

[48] K. Fluiter, A.L. Ten Asbroek, M.B. De Wissel, M.E. Jakobs, M. Wissenbach, H. Olsson, 0. Olsen, H. Oerum, F. Baas, In vivo tumor growth inhibition and biodistribution 
studies of locked nucleic acid (LNA) antisense oligonucleotides, Nucleic Acids Res. 31 (2003) 953-962.

[49] E.E. Swayze, A.M. Siwkowski, E.V. Wancewciz, M.T. Migawa, T.K. Wyrzykiewicz, G. Hung, B.P Monia, C.F. Bennett, Antisense oligonucleotides containing locked nucleic acid improve potency but cause significant hepatotoxicity in animals, Nucleic Acids Res. 35 (2007) 687-700.

[50] Y. Zou, P. Tiller, I.W. Chen, M. Beverly, J. Hochman, Metabolite identification of small interfering RNA duplex by high-resolution accurate mass spectrometry, Rapid Commun. Mass Spectrom. 22 (2008) 1871-1881.

[51] R.I. Hogrefe, A.V. Lebedev, G. Zon, K.F. Pirollo, A. Rait, Q. Zhou, W. Yu, E.H. Chang, Chemically modified short interfering hybrids (siHYBRIDS): nanoimmunoliposome delivery in vitro and in vivo for RNAi of HER-2, Nucleosides Nucleotides Nucleic Acids 25 (2006) 889-907.

[52] K.F. Pirollo, A. Rait, Q. Zhou, S.H. Hwang, J.A. Dagata, G. Zon, R.I. Hogrefe, G. Palchik, E.H. Chang, Materializing the potential of small interfering RNA via a tumor targeting nanodelivery system, Cancer Res. 67 (2007) 2938-2943.

[53] K. Ui-Tei, Y. Naito, S. Zenno, K. Nishi, K. Yamato, F. Takahashi, A. Juni, K. Saigo, Functional dissection of siRNA sequence by systematic DNA substitution: modified 
siRNA with a DNA seed arm is a powerful tool for mammalian gene silencing with significantly reduced off-target effect, Nucleic Acids Res. 36(7) (2008) 2136-2151.

[54] A.L. Jackson, J. Burchard, D. Leake, A. Reynolds, J. Schelter, J. Guo, J.M. Johnson, L. Lim, J. Karpilow, K. Nichols, W. Marshall, A. Khvorova, P.S. Linsley, Position-specific chemical modification of siRNAs reduces "off-target" transcript silencing, RNA 12 (2006) 1197-1205.

[55] N. Puri, X. Wang, R. Varma, C. Burnett, L. Beauchamp, D.M. Batten, M. Young, V. Sule, K. Latham, T. Sendera, C. Echeverri, C. Sachse, S. Magdaleno, LNA incorporated siRNAs exhibit lower off-target effects compared to 2'-OMethoxy in cell phenotypic assays and microarray analysis, Nucleic Acids Symp Ser (Oxf). 52 (2008) 25-26.

[56] P.Y. Chen, L. Weinmann, D. Gaidatzis, Y. Pei, M. Zavolan, T. Tuschl, G. Meister, Strandspecific 50-0-methylation of siRNA duplexes controls guide strand selection and targeting specificity. RNA 14 (2008) 263-274.

[57] J.B. Bramsen, M.B. Laursen, C.K. Damgaard, S.W. Lena, B.R. Babu, J. Wengel, J. Kjems, Improved silencing properties using small internally segmented interfering RNAs, Nucleic Acids Res. 35 (17) (2007) 5886-5897. 
[58] M. Sioud, G. Furset, L. Cekaite, Suppression of immunostimulatory siRNA-driven innate immune activation by 2'-modified RNAs, Biochem Biophys Res Commun. 361 (2007) 122-126.

[59] A.L. Jackson, P.S. Linsley, Recognizing and avoiding siRNA off-target effects for target identification and therapeutic application, Nat. Rev. Drug Discov. 9 (1) (2010) 57 67.

[60] B. Ozpolat, A.K. Sood, G. Lopez-Berestein, Liposomal siRNA nanocarriers for cancer therapy, Adv Drug Deliv Rev. 66 (2014)110-116.

[61] J. Zhou, K.T. Shum, J.C. Burnett, J.J. Rossi, Nanoparticle-based delivery of RNAi therapeutics: progress and challenges, Pharmaceuticals (Basel) 6 (1) (2013) 85107.

[62] Y. Minakuchi, F. Takeshita, N. Kosaka, H. Sasaki, Y. Yamamoto, M. Kouno, K. Honma, S. Nagahara, K. Hanai, A. Sano, et al., Atelocollagen-mediated synthetic siRNA delivery for effective gene silencing in vitro and in vivo, Nucleic Acids Res. 32 (2004) e109.

[63] W.B. Tan, S. Jiang, Y. Zhang, Quantum-dot based nanoparticles for targeted silencing of HER2/neu gene via RNA interference, Biomaterials 28 (8) (2007) 1565-1571. 
[64] J.H. Lee, K. Lee, S.H. Moon, Y. Lee, T.G. Park, J. Cheon, All-in-one target-cell-specific magnetic nanoparticles for simultaneous molecular imaging and siRNA delivery, Angew. Chem. Int. Ed. Engl. 48 (23) (2009) 4174-4179.

[65] D. Yu, P. Peng, S.S. Dharap, Y.Wang, M. Mehlig, P. Chandna, et al., Antitumor activity of poly(ethylene glycol)-camptothecin conjugate: the inhibition of tumor growth in vivo, J. Control. Release 110 (2005) 90-102.

[66] S. Dokka, D. Toledo, X. Shi, V. Castranova, Y. Rojanasakul, Oxygen radical-mediated pulmonary toxicity induced by some cationic liposomes, Pharm. Res. 17 (5) (2000) 521.

[67] S. Spagnou, A.D. Miller, M. Keller, Lipid carriers of siRNA: differences in the formulation, cellular uptake, and delivery with plasmid DNA, Biochemistry 43 (2004) 13348-13356.

[68] H. Lv, S. Zhang, B. Wang, S. Cui, J. Yan, Toxicity of cationic lipids and cationic polymers in gene delivery, J. Control. Release 114 (2006) 100-109.

[69] C.N. Landen Jr., A. Chavez-Reyes, C. Bucana, R. Schmandt, M.T. Deavers, G. LopezBerestein, A.K. Sood, Therapeutic EphA2 gene targeting in vivo using neutral liposomal small interfering RNA delivery, Cancer Res. 65 (2005) 6910-6918. 
[70] J. Halder, A.A. Kamat, C.N. Landen Jr., L.Y. Han, S.K. Lutgendorf, Y.G. Lin, W.M. Merritt, N.B. Jennings, A. Chavez-Reyes, R.L. Coleman, D.M. Gershenson, R. Schmandt, S.W. Cole, G. Lopez-Berestein, A.K. Sood, Focal adhesion kinase targeting using in vivo short interfering RNA delivery in neutral liposomes for ovarian carcinoma therapy, Clin. Cancer Res. 12 (2006) 4916-4924.

[71] M.J. Gray, G. Van Buren, N.A. Dallas, L. Xia, X. Wang, A.D. Yang, R.J. Somcio, Y.G. Lin, S. Lim, F. Fan, L.S. Mangala, T. Arumugam, C.D. Logsdon, G. Lopez-Berestein, A.K. Sood, L.M. Ellis, Therapeutic targeting of neuropilin-2 on colorectal carcinoma cells implanted in the murine liver, J. Natl. Cancer Inst. 100 (2008) 109-120.

[72] L.J. Shao, I. Tekedereli, J. Wang, E. Yuca, S. Tsang, A.K. Sood, G. Lopez-Berestein, B. Ozpolat, M.M. Ittmann, Highly specific targeting of the TMPRSS2/ERG fusion gene using liposomal nanovectors, Clin. Cancer Res. 18 (24) (2012) 6648-6657.

[73] W.M. Merritt, Y.G. Lin, W.A. Spannuth, M.S. Fletcher, A.A. Kamat, L.Y. Han, C.N. Landen, N. Jennings, K. De Geest, R.R. Langley, G. Villares, A. Sanguino, S.K. Lutgendorf, G. Lopez-Berestein, M.M. Bar-Eli, A.K. Sood, Effect of interleukin-8 gene silencing with liposome-encapsulated small interfering RNA on ovarian cancer cell growth, J. Natl. Cancer Inst. 100 (2008) 359-372.

[74] I. Tekedereli, S.N. Alpay, U. Akar, E. Yuca, C. Aguayo-Rodriguez, H.D. Han, A.K. Sood, G. Lopez-Berestein, B. Ozpolat, Therapeutic silencing of Bcl-2 by systemically 
administered siRNA nanotherapeutics inhibits tumor growth by autophagy and apoptosis and enhances the efficacy of chemotherapy in orthotopic xenograft models of ER (-) and ER (+) breast cancer, Mol. Ther. Nucleic Acids. 2 (2013) e121.

[75] T.S. Zimmermann, A.C. Lee, A. Akinc, B. Bramlage, D. Bumcrot, M.N. Fedoruk, J. Harborth, J.A. Heyes, L.B. Jeffs, M. John, A.D. Judge, K. Lam, K. McClintock, L.V. Nechev, L.R. Palmer, T. Racie, I. Röhl, S. Seiffert, S. Shanmugam, V. Sood, J. Soutschek, I. Toudjarska, A.J. Wheat, E. Yaworski, W. Zedalis, V. Koteliansky, M. Manoharan, H.P. Vornlocher, I. MacLachlan, RNAi-mediated gene silencing in non-human primates, Nature 441 (2006) 111-114.

[76] H.R. Kim, I.K. Kim, K.H. Bae, S.H. Lee, Y. Lee, T.G. Park, Cationic solid lipid nanoparticles reconstituted from low density lipoprotein components for delivery of siRNA, Mol. Pharm. 5 (2008) 622-631.

[77] A. Akinc, A. Zumbuehl, M. Goldberg, et al., A combinatorial library of lipid-like materials for delivery of RNAi therapeutics, Nat. Biotechnol. 26 (5) (2008) 561-569.

[78] C. Wolfrum, S. Shi, K.N. Jayaprakash, et al., Mechanisms and optimization of in vivo delivery of lipophilic siRNAs, Nat. Biotechnol. 25 (2007) 1149-1157. 
[79] G.J. Villares, M. Zigler, H. Wang, et al., Targeting melanoma growth and metastasis with systemic delivery of liposome-incorporated protease-activated receptor-1 small interfering RNA, Cancer Res. 68 (2008) 9078-9086.

[80] W.B. Tan, S. Jiang, Y. Zhang, Quantum-dot based nanoparticles for targeted silencing of HER2/neu gene via RNA interference, Biomaterials 28 (8) (2007) 1565-1571.

[81] A.M. Derfus, A.A. Chen, D.H. Min, E. Ruoslahti, S.N. Bhatia, Targeted quantum dot conjugates for siRNA delivery, Bioconjug Chem. 200718 (5) (2007) 1391-1396.

[82] J.C. Burnett, J.J. Rossi, K. Tiemann, Current progress of siRNA/shRNA therapeutics in clinical trials. Biotechnol J. 6 (9) (2011) 1130-1146.

[83] J.C. Burnett, J.J. Rossi, RNA-based therapeutics: current progress and future prospects. Chem Biol. 19(1) (2012) 60-71.

[84] P.K. Kaiser, R.C. Symons, S.M. Shah, E.J. Quinlan, H. Tabandeh, D.V. Do, G. Reisen, J.A. Lockridge, B. Short, R. Guerciolini, Q.D. Nguyen; Sirna-027 Study Investigators, RNAi-based treatment for neovascular age-related macular degeneration by Sirna027. Am J Ophthalmol. 150 (1) (2010) 33-39.

[85] Q.D. Nguyen, R.A. Schachar, C.I. Nduaka, M. Sperling, A.S. Basile, K.J. Klamerus, K. ChiBurris, E. Yan, D.A. Paggiarino, I. Rosenblatt, A. Khan, R. Aitchison, S.S. Erlich, PF- 
04523655 Study Group, Phase 1 dose-escalation study of a siRNA targeting the RTP801 gene in age-related macular degeneration patients. Eye (Lond). 26(8) (2012) 1099-1105.

[86] M.R. Zamora, M. Budev, M. Rolfe, J. Gottlieb, A. Humar, J. Devincenzo, A. Vaishnaw, J. Cehelsky, G. Albert, S. Nochur, J.A. Gollob, A.R. Glanville, RNA interference therapy in lung transplant patients infected with respiratory syncytial virus. Am J Respir Crit Care Med. 183(4) (2011) 531-538.

[87] S.A. Leachman, R.P. Hickerson, M.E. Schwartz, E.E. Bullough, S.L. Hutcherson, K.M. Boucher, C.D. Hansen, M.J. Eliason, G.S. Srivatsa, D.J. Kornbrust, F.J. Smith, W.I. McLean, L.M. Milstone, R.L. Kaspar, First-in-human mutation-targeted siRNA phase Ib trial of an inherited skin disorder. Mol Ther. 18(2)(2010)442-446.

[88] T. Martínez, M.V. González, I. Roehl, N. Wright, C. Pañeda, A.I. Jiménez, In vitro and in vivo efficacy of SYL040012, a novel siRNA compound for treatment of glaucoma. Mol Ther. 22(1) (2014) 81-91.

[89] E. Zorde Khvalevsky, R. Gabai, I.H. Rachmut, E. Horwitz, Z. Brunschwig, A. Orbach, Shemi A, T. Golan, A.J. Domb, E. Yavin, H. Giladi, L. Rivkin, A. Simerzin, R. Eliakim, A. Khalaileh, A. Hubert, M. Lahav, Y. Kopelman, E. Goldin, A. Dancour, Y. Hants, S. Arbel-Alon, R. Abramovitch, A. Shemi, E. Galun, Mutant KRAS is a druggable 
target for pancreatic cancer. Proc Natl Acad Sci U. S. A. 110(51) (2013) 2072320728.

[90] M.E. Davis, J.E. Zuckerman, C.H.J. Choi, D. Seligson, A. Tolcher, C.A. Alabi, Y. Yen, J.D. Heidel, A. Ribas, Evidence of RNAi in humans from systemically administered siRNA via targeted nanoparticles, Nature 464 (2010) 1067.

[91] J.E. Zuckerman, I. Gritli, A. Tolcher, J.D. Heidel, D. Lim, R. Morgan, B. Chmielowski, A. Ribas, M.E. Davis, Y. Yen, Correlating animal and human phase Ia/Ib clinical data with CALAA-01, a targeted, polymer-based nanoparticle containing siRNA. Proc Natl Acad Sci U. S. A. 111(31) (2014) 11449-11454.

[92] D. Strumberg, B. Schultheis, U. Traugott, C. Vank, A. Santel, O. Keil, K. Giese, J. Kaufmann, J. Drevs. Phase I clinical development of Atu027, a siRNA formulation targeting PKN3 in patients with advanced solid tumors. Int J Clin Pharmacol Ther. 50(1)(2012)76-78.

[93] T. Coelho, D. Adams, A. Silva, P. Lozeron, P.N. Hawkins, T. Mant, J. Perez, J. Chiesa, S. Warrington, E. Tranter, M. Munisamy, R. Falzone, J. Harrop, J. Cehelsky, B.R. Bettencourt, M. Geissler, J.S. Butler, A. Sehgal, R.E. Meyers, Q. Chen, T. Borland, R.M. Hutabarat, V.A. Clausen, R. Alvarez, K. Fitzgerald, C. Gamba-Vitalo, S.V. Nochur, A.K. Vaishnaw, D.W. Sah, J.A. Gollob, O.B. Suhr, Safety and efficacy of RNAi therapy for transthyretin amyloidosis. N Engl J Med. 369(9)(2013)819-829. 
[94] K. Fitzgerald, M. Frank-Kamenetsky, S. Shulga-Morskaya, A. Liebow, B.R. Bettencourt, J.E. Sutherland, R.M. Hutabarat, V.A. Clausen, V. Karsten, J. Cehelsky, S.V. Nochur, V. Kotelianski, J. Horton, T. Mant, J. Chiesa, J. Ritter, M. Munisamy, A.K. Vaishnaw, J.A. Gollob, A. Simon, Effect of an RNA interference drug on the synthesis of proprotein convertase subtilisin/kexin type 9 (PCSK9) and the concentration of serum LDL cholesterol in healthy volunteers: a randomised, single-blind, placebocontrolled, phase 1 trial. Lancet. 383(9911)(2014)60-68.

[95] J.D. Heidel, Z. Yu, J.Y. Liu, S.M. Rele, Y. Liang, R.K. Zeidan, D.J. Kornbrust, M.E. Davis, Administration in non-human primates of escalating intravenous doses of targeted nanoparticles containing ribonucleotide reductase subunit M2 siRNA, Proc. Natl. Acad. Sci. U. S. A. 104 (2007) 5715-5721.

[96] A.M. Flenniken, N.W. Gale, G.D. Yancopoulos, D.G. Wilkinson, Distinct and overlapping expression patterns of ligands for Eph-related receptor tyrosine kinases during mouse embryogenesis. Dev Biol. 179 (1996) 382-401.

[97] R.A. Lindberg, T. Hunter, cDNA cloning and characterization of eck, an epithelial cell receptor protein-tyrosine kinase in the eph/elk family of protein kinases. Mol Cell Biol. 10(12)(1990)6316-6324. 
[98] D.P. Zelinski, N.D. Zantek, J.C. Stewart, A.R. Irizarry, M.S. Kinch, EphA2 overexpression causes tumorigenesis of mammary epithelial cells. Cancer Res. 61(5)(2001)2301-2306.

[99] J. Walker-Daniels, K. Coffman, M. Azimi, J.S. Rhim, D.G. Bostwick, P. Snyder, B.J. Kerns, D.J. Waters, M.S. Kinch, Overexpression of the EphA2 tyrosine kinase in prostate cancer. Prostate 41 (1999) 275-280.

[100] D.J. Easty, D.C. Bennett, Protein tyrosine kinases in malignant melanoma. Melanoma Res. 10(5)(2000)401-411.

[101] T. Nemoto, K. Ohashi, T. Akashi, J.D. Johnson, K. Hirokawa, Overexpression of protein tyrosine kinases in human esophageal cancer. Pathobiology 65 (1997) 195-203.

[102] M.S. Kinch, M.B. Moore, D.H. Harpole Jr., Predictive value of the EphA2 receptor tyrosine kinase in lung cancer recurrence and survival. Clin Cancer Res. $9(2)(2003) 613-618$.

[103] A.R. Hess, E.A. Seftor, L.M. Gardner, K. Carles-Kinch, G.B. Schneider, R.E. Seftor, M.S. Kinch, M.J. Hendrix, Molecular regulation of tumor cell vasculogenic mimicry by tyrosine phosphorylation: role of epithelial cell kinase (Eck/EphA2). Cancer Res. 61(8)(2001)3250-3255. 
[104] R. Siegel, J. Ma, Z. Zou, A. Jemal, Cancer statistics, 2014. CA Cancer J Clin. 64(1)(2014)9-29.

[105] W.P. McGuire, W.J. Hoskins, M.F. Brady, P.R. Kucera, E.E. Partridge, K.Y. Look, D.L. Clarke-Pearson, M. Davidson, Cyclophosphamide and cisplatin compared with paclitaxel and cisplatin in patients with stage III and stage IV ovarian cancer. N Engl J Med. 334(1)(1996)1-6.

[106] A. du Bois, J.P. Neijt, J.T. Thigpen, First line chemotherapy with carboplatin plus paclitaxel in advanced ovarian cancer--a new standard of care? Ann Oncol. 10(Suppl 1) (1999) 35-41.

[107] P.H. Thaker, M. Deavers, J. Celestino, A. Thornton, M.S. Fletcher, C.N. Landen, M.S. Kinch, P.A. Kiener, A.K. Sood, EphA2 expression is associated with aggressive features in ovarian carcinoma. Clin Cancer Res. 10 (2004) 5145-5150.

[108] L. Han, Z. Dong, Y. Qiao, G.B. Kristensen, R. Holm, J.M. Nesland, Z. Suo, The clinical significance of EphA2 and Ephrin A-1 in epithelial ovarian carcinomas. Gynecol Oncol. 99(2)(2005)278-286.

[109] C.N. Landen, M.S. Kinch, A.K. Sood, EphA2 as a target for ovarian cancer therapy. Expert Opin Ther Targets. 9(6)(2005)1179-1187. 
[110] Y.G. Lin, L.Y. Han, A.A. Kamat, W.M. Merritt, C.N. Landen, M.T. Deavers, M.S. Fletcher, D.L. Urbauer, M.S. Kinch, A.K. Sood, EphA2 overexpression is associated with angiogenesis in ovarian cancer. Cancer. 109(2)(2007)332-340.

[111] J. Walker-Daniels, A.R. Hess, M.J. Hendrix, M.S. Kinch, Differential regulation of EphA2 in normal and malignant cells. Am J Pathol. 162(4)(2003)1037-1042.

[112] C.N. Landen Jr., C. Lu, L.Y. Han, K.T. Coffman, E. Bruckheimer, J. Halder, L.S. Mangala, W.M. Merritt, Y.G. Lin, C. Gao, R. Schmandt, A.A. Kamat, Y. Li, P. Thaker, D.M. Gershenson, N.U. Parikh, G.E. Gallick, M.S. Kinch, A.K. Sood, Efficacy and antivascular effects of EphA2 reduction with an agonistic antibody in ovarian cancer. J Natl Cancer Inst. 98(21)(2006)1558-1570.

[113] R.L. Pratt, M.S. Kinch, Activation of the EphA2 tyrosine kinase stimulates the MAP/ERK kinase signaling cascade. Oncogene. 21(50)(2002)7690-7699.

[114] H. Shen, C. Rodriguez-Aguayo, R. Xu, V. Gonzalez-Villasana, J. Mai, Y. Huang, G. Zhang, X. Guo, L. Bai, G. Qin, X. Deng, Q. Li, D.R. Erm, B. Aslan, X. Liu, J. Sakamoto, A. ChavezReyes, H.D. Han, A.K. Sood, M. Ferrari, G. Lopez-Berestein, Enhancing chemotherapy response with sustained EphA2 silencing using multistage vector delivery, Clin Cancer Res. 19 (7) (2013) 1806-1815. 
[115] D. Jiang, L.S. Mangala, H. Wang, S. Wu, L.G. Rao, C. Rodriguez-Aguayo, S. Pradeep, D.E. Volk, G.l Lopez-Berestein, A.K. Sood, Tumor vasculature targeting using cell-specific thioaptamer decorated chitosan nanoparticle [abstract], Proceedings of the 105th Annual Meeting of the American Association for Cancer Research; 2014 Apr 5-9; San Diego, CA. Philadelphia (PA): AACR; Cancer Res 2014;74(19 Suppl): Abstract nr 4468.

[116] H.D. Han, L.S. Mangala, J.W. Lee, M.M.Shahzad, H.S. Kim, D. Shen, E.J. Nam, E.M. Mora, R.L. Stone, C. Lu, Targeted gene silencing using RGD-labeled chitosan nanoparticles, Clinical Cancer Research. 16 (2010) 3910-3922.

[117] A. Tari, M. Khodadadian, D. Ellerson, A. Deisseroth, G. Lopez-Berestein, Liposomal delivery of oligodeoxynucleotides. Leuk Lymphoma. 21(1-2)(1996)93-97.

[118] A.M. Tari, M. Andreeff, H.D. Kleine, G. Lopez-Berestein, Cellular uptake and localization of liposomal-methylphosphonate oligodeoxynucleotides, J Mol Med (Berl). 74(10)( 1996) 623-628.

[119] Y. Gutiérrez-Puente, A.M. Tari, C. Stephens, M. Rosenblum, R.T. Guerra, G. LopezBerestein, Safety, pharmacokinetics, and tissue distribution of liposomal P-ethoxy antisense oligonucleotides targeted to Bcl-2, J Pharmacol Exp Ther. 291(2)(1999) 865-869. 
[120] A.M. Tari, Y. Gutiérrez-Puente, G. Monaco, C. Stephens, T. Sun, M. Rosenblum, J. Belmont, R. Arlinghaus, G. Lopez-Berestein, Liposome-incorporated Grb2 antisense oligodeoxynucleotide increases the survival of mice bearing bcr-abl-positive leukemia xenografts, Int J Oncol. 31(5)(2007)1243-1250.

[121] M.Ohanian, H.M. Kantarjian, F. Ravandi, G. Borthakur, G. Garcia-Manero, M. Andreeff, E. Jabbour, M. Konopleva, S. O'Brien, A. Quintas-Cardama, B. G. Somer, A. Tari, S.Verstovsek, W.G. Wierda, J. E. Cortes, Safety, pharmacokinetics, and efficacy Of BP100-1.01 (liposomal Grb-2 antisense oligonucleotide) In patients with refractory or relapsed acute myeloid leukemia (AML), Philadelphia chromosome positive chronic myelogenous leukemia (CML), acute lymphoblastic leukemia (ALL), and myelodysplastic syndrome (MDS), American Society of Hematology 55th Annual meeting and Exposition, New Orleans LA, December 7-10, 2013, Abstract nr: 2679.

[122] https://clinicaltrials.gov/ct2/show/NCT01591356 (January 2, 2015). 


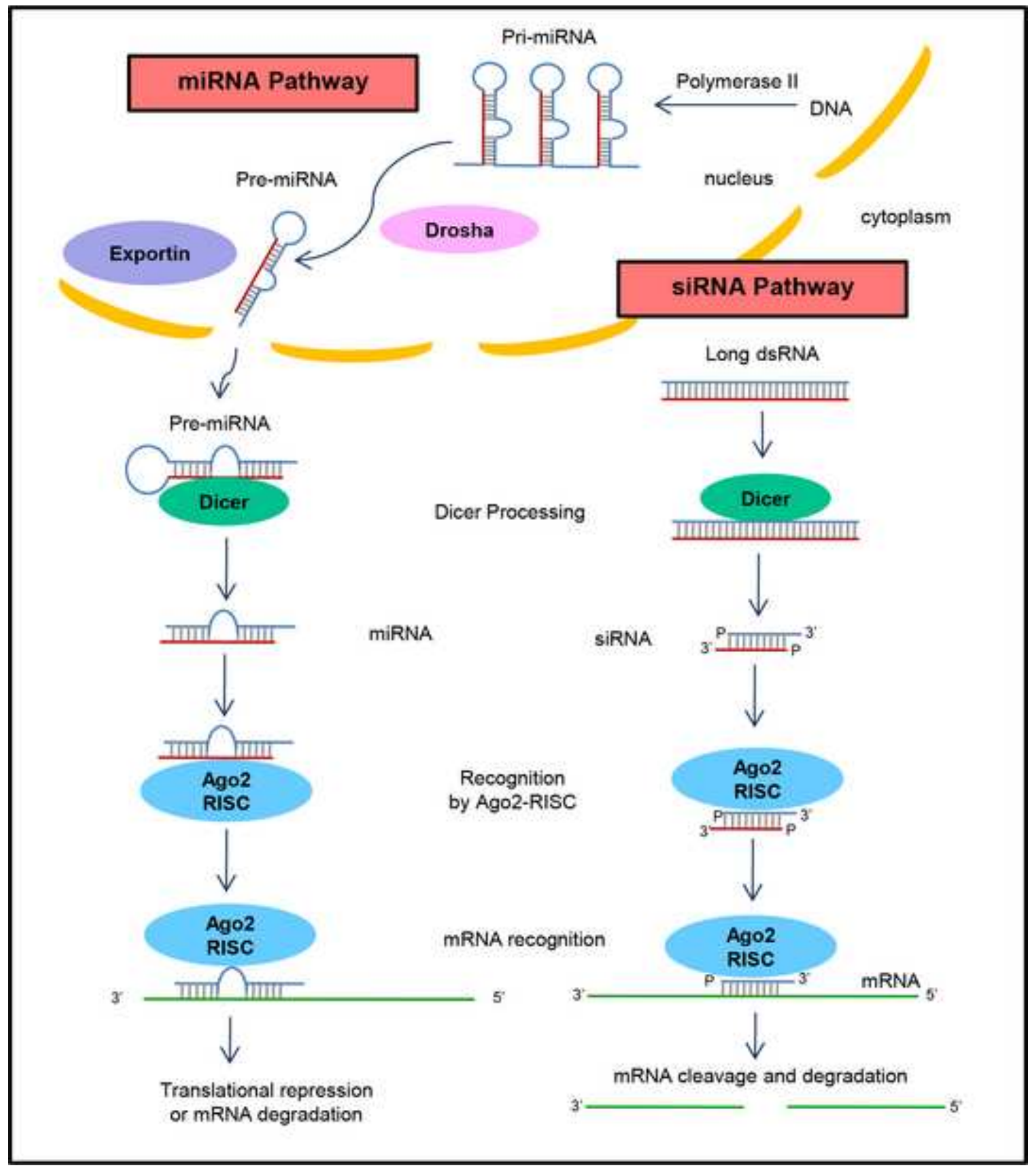

